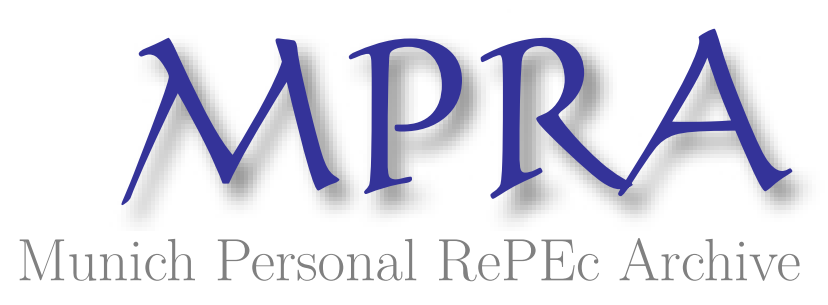

\title{
Investment-Specific Technology Shocks in a Small Open Economy
}

Mulraine, Millan L. B.

January 2005

Online at https://mpra.ub.uni-muenchen.de/7/

MPRA Paper No. 7, posted 20 Sep 2006 UTC 


\title{
Investment-Specific Technology Shocks in a Small Open Economy*
}

\author{
Millan L. B. Mulraine ${ }^{\dagger}$
}

August 2006

\begin{abstract}
In this paper we examine the behavioral responses of key macroeconomic variables in Canada to exogenous innovations to investment specific technology. This is done by developing a stylized international real business cycle model which is simulated to explore its ability to shed new light on the dynamic behavior of the standard small open economy. The results indicate that this model can quantitatively replicate the key dynamic features of the post-war Canadian economy, and thus shocks to investment-specific technology can be considered an important propagation mechanism for studying and understanding modern macroeconomic dynamics in small open economies. Moreover, when the model was augmented with an endogenous utilization rate it was able to generate the counter-cyclical behavior of the external accounts - without appealing to an adjustment cost parameter and/or a propagation mechanism whose volatility and persistence are artificially low.
\end{abstract}

Keywords: Endogenous rate of time preference, Investment-specific shocks, Relative price of investment goods.

JEL Classification: E32, E37, F41

${ }^{*}$ This paper forms part of my Ph.D. Economics thesis at the University of Toronto. I wish to thank Shouyong Shi and Gueorgui Kambourov for their supervision of this effort, and the many others who offered helpful suggestions and comments. All remaining errors are mine.

${ }^{\dagger}$ Corresponding address: Department of Economics, University of Toronto, 150 St. George Street, Toronto, ON M5S 3G7, Canada. Tel: 1 (416) 824 8069, Email: millan.mulraine@utoronto.ca 


\section{Introduction:}

At the core of the standard Real Business Cycle (RBC) research agenda is the notion that economic fluctuations are driven principally by exogenous changes to real factors in the economy. More generally, the primary focus of this research agenda has been based on the idea that macroeconomic or business cycle fluctuations are caused by large and cyclically volatile exogenous shocks to total factor productivity (TFP) - which can be captured by the Hicksianneutral Solow residuals. Indeed, since its inception in the 1980s, the RBC research program has grown spectacularly to become a significant area of research in macroeconomics, and its concepts and methods becoming well defused into the mainstream macroeconomic analysis of economic dynamics. In fact, its success was not only due to the widespread theoretical appeal of this approach but also to its exceptional empirical performance.

Despite these phenomenal successes, the practice of employing the Hicksian-neutral Solow residuals as the sole source of aggregate productivity innovations in standard small open economy models suffers from numerous inherent deficiencies. Most prominent among these are the imposition of the empirically untenable assumption that the relative price of investment goods (in terms of consumption goods) is one, and constant over time; and their inability to replicate the counter-cyclical movements observed in the external accounts of the OECD economies without appealing to an adjustment cost parameter, and/or a propagation mechanism whose volatility and persistence are artificially low.

This standard assertion of a constant, unitary relative price of investment goods is particularly significant since it conflicts with the overwhelming empirical evidence which shows that the relative price of investment goods in terms of consumption goods has fallen consistently over time in most OECD countries during the post-war period. It is this feature of modern economies which highlights the pivotal link between the response of domestic investment flows to movements in investment price and macroeconomic dynamics, as outlined by Baxter (1995). As such, by attributing all observed macroeconomic fluctuations to changes in the total factor productivity invariably obviates the fact that innovations to the relative price of investment goods over time may itself be an important and indispensable source of macroeconomic dynamics.

Furthermore, the standard small open economy model driven by innovations to TFP has 
been unable to simultaneously replicate the counter-cyclical movements in the ratios of the current account to output and the trade balance to output, seen in the data for OECD countries, without a very low adjustment cost parameter and appealing to a propagation mechanism whose volatility and persistence are artificially low. In Mendoza (1991) and Schmitt-Grohé and Uribe (2003), for example, these statistics were generated by simulating the model to match the volatility and first-order serial correlation of output. As will become apparent later, the calibrated parameter values used in these studies are significantly lower than their empirical counterpart in the Canadian data and may in fact be driving the counter-cyclical behavior of the external account observed in their results. In light of this deficiency in the standard models, it will be shown that when the volatility and persistence of the innovations to TFP and the investment-specific technology (IST) are estimated from the Canadian data, the IST shock model outperforms the TFP shock framework in matching the counter-cyclical behavior of the external accounts.

The objective of this paper, therefore, will be to extend the literature on the dynamic behavior of the standard small open economy by considering shocks to IST captured by innovations to the relative price of investment goods, induced by exogenous movements in the efficiency in the production of next period's capital goods - or investment-specific technology (IST) shocks. It will be shown that shocks to IST can account for a significant fraction of business cycle fluctuations in Canada, and thus can be considered an important propagation mechanism for studying and understanding modern macroeconomic dynamics in the standard small open economy. The approach presented here is particularly important since it provides an empirically relevant measure of productivity innovations that has been largely ignored in the open economy literature. A very notable exception to this omission is the work of Boileau (2002) in which shocks to IST was used to match moments in a two-country setup. ${ }^{1}$ Additionally, the paper offers a measure of technological propagation that avoids the now pervasive criticisms that have been leveled at studies that rely on the Solow-residuals as the sole source of productivity innovations.

Following the work of Greenwood et al. (2000), this paper espouses the use of capital-

\footnotetext{
${ }^{1}$ The work of Letendre and Luo (2005) is identical in orientation to the framework being considered here. Their article, however, was brought to my attention subsequent to the completion of this paper. As such, the first draft of this paper was written independently - though concurrently, to their article.
} 
embodied technological changes as the main contributor to economic fluctuations in the economy considered. Indeed, Greenwood et al. (1997) has shown investment-specific shocks to be the unique source of trend in the real price of investment goods (the main determinant in the formation of new capital) in the US. More importantly, Greenwood et al. (1988, 2000) have shown that shocks to IST can account for over $30 \%$ of output fluctuation in the postwar US data. Further evidence on the impact of innovations to IST on the business cycle behavior of the US economy has been provided by Fisher (2003), who - using more recent data - finds that investment-specific technology shock can accounts for over $50 \%$ of business cycle variation in hours worked, compared to only $6 \%$ accounted for by shock to total factor productivity. These results are quite striking when one considers that investment in new machinery and equipment in the United States accounts for only $7 \%$ of GNP.

The theoretical motivation for this redefinition of productivity innovation has a somewhat Keynesian flavor. It was Keynes (1936), who motivated this thinking by asserting that shocks to the marginal productivity (or efficiency) of investment goods is the main propagating mechanism for generating output fluctuations. His premise was based on the fact that shocks to the efficiency of investment goods affected the cost of investment goods relative to consumption goods, thereby affecting the investment decisions of private agents and consequently employment and output. The intuition for this observation becomes obvious when one considers that investment-specific technological progress results in the creation of new and more efficient investment goods which make capital equipment and other forms of capital goods cheaper (relative to consumption goods) - thereby igniting the increased accumulation of machinery and equipment, for example, in both the short and long run. In essence, the basic premise of this view is that the introduction of new and more efficient investment goods can be seen as the main source of productivity growth in the economy and hence it has become necessary to disentangle this form of technical progress from the more traditional Hicksian-neutral Solow residuals.

The remainder of the paper proceeds as follows. The next section will examine the properties of the relative price of investment in Canada. In Section 2 we describe and discuss the structure of the model to be considered in this analysis and explain the calibration and simulation procedures to be implemented, while Section 4 will discuss the simulated results and associated impulse responses. Section 5 will provide the conclusions drawn from the analysis 
and offer avenues for future extensions of this approach.

\section{The Relative Price of Investment in Canada:}

The importance of this new measure of technological innovation in the Canadian context is borne out by its ability to explain the consistently declining relative price of investment goods (relative to consumption goods), and the negative co-movement between the relative price of machinery and equipment ${ }^{2}$ and the quantity of new machinery and equipment observed in the post-war Canadian data. As is evident in Figure 1, the Canadian economy experienced a consistent downward trend in the relative price of investment goods since 1981, with an evident concomitant increase in aggregate investment over the same period.

This inverse relationship between the relative price of investment goods and aggregate investment in machinery and equipment is even more pronounced when these series are considered at business cycle frequencies ${ }^{3}$. As is evident in Figure 1, the business cycle components of the relative price of investment goods in Canada and that for gross investment in machinery and equipment are clearly inversely related - with periods of downward movement in the relative price being associated with a concurrent upward movement in the level total investment in Canada. In fact, the correlation coefficient for this relationship is -0.532 with a p-value of 0.009 - meaning that this inverse relationship is statistically significant at the $1 \%$ level.

In light of this strong evidence on the inverse relationship between investment and the relative price of investment goods in levels and at business cycle frequencies - and given the pivotal role that the investment decisions of agents play in macroeconomic fluctuations, this paper aims to provide evidence to show that shocks IST captured by innovations to the relative price of investment goods can account for a significant portion of macroeconomic fluctuations in Canada. The paper will provide the natural open economy extension for the work of Greenwood et al. (1988, 1997, 2000) and Fisher (1999, 2003); which have focussed exclusively on the dynamics associated with a closed economy. This extension is particularly important since it will offer a new dimension for looking at the dynamic behavior of the standard small

\footnotetext{
${ }^{2}$ For this analysis the relative price is defined as the ratio of the industrial price index (IPI) for machinery and equipment to the consumer price index (CPI) for non-durable goods. See Appendix for a discussion on the data series used in this analysis.

${ }^{3}$ The business cycle data is generated from the H-P filtered residual of the actual annual data series.
} 
open economy model. Indeed, for an open economy with access to international capital market this type of propagation is expected to have significant business cycle implications by virtue of the fact that access to external financial assets mitigates the negative substitution effect that will generally be the case in an otherwise closed economy.

The analysis conducted here is similar to the work of Mendoza (1991), Schmitt-Grohé and Uribe (2003), and Letendre (2004); where a stylized small open economy is subjected to exogenous innovations to total factor productivity. This paper, therefore, aims to re-examine the behavioral responses of key macroeconomic variables in Canada to exogenous shocks to the efficiency in the production of investment goods and total factor productivity. It will do so by developing a simple two-sector calibrated international real business cycle model which will be simulated to explore its ability to shed new light on the behavior of the standard small open economy to shocks to the efficiency in the production of capital goods and TFP. In this framework attention will be paid to the ability of a stylized model with shocks to IST to replicate key moments in the Canadian data and an examination into the associated impulse responses of key variables will be conducted.

\section{The Model and Solution Techniques:}

Consider a small open economy populated by a large number of infinitely-lived identical agents acting as price takers in all markets in which they participate. These residents are connected to the rest of the world only through their access to a frictionless incomplete international capital market and a market for a tradeable composite consumption good.

Of crucial importance here is the fact trade in these financial instruments across international borders will only be for consumption smoothing and not risk-sharing or insurance against these shocks. As such, the financial contracts engaged in by agents cannot be made contingent on the realization of the states of nature among these world residents. More importantly, given that the economy is small relative to the rest of the world it takes the interest rate on the international asset as given. As a result of this, resident in this economy will allocate their holding of assets between domestic physical capital and international financial capital in a manner that will equalize their respective net marginal rates of return. 


\subsection{Preferences:}

The preference structure for individuals in the economy who allocate the consumption good $c_{t}$ inter-temporally and labor effort $l_{t}$ to maximize a discrete time analogue of an Epstein and Hynes (1983) recursive utility is of the form given by:

$$
U(C)=E_{0}\left[\sum_{t=0}^{\infty}\left\{u\left(c_{t}, l_{t}\right) \exp \left(-\sum_{\tau=0}^{t-1} v\left(c_{\tau}, l_{\tau}\right)\right)\right\}\right]
$$

Where the structure of the preference function is such that utility function $U$ assigns utility $U(C)$ to each consumption and leisure path given by $c_{t}, c_{t+1}, c_{t+2}, \ldots, c_{\infty}$ and $l_{t}, l_{t+1}, l_{t+2}, \ldots, l_{\infty}$, respectively.

Following Greenwood et al. (1988), the instantaneous utility function will be of the form given by:

$$
u\left(c_{t}, l_{t}\right)=\frac{\left[c_{t}-\frac{l_{t}^{\omega}}{\omega}\right]^{1-\gamma}-1}{1-\gamma} \quad \omega, \gamma>1
$$

where $u($.$) is bounded below, u^{\prime}()>$.0 and $u^{\prime}(0)=\infty$, and the endogenous subjective time preference factor ${ }^{4}$ given by:

$$
v\left(c_{\tau}, l_{\tau}\right)=\left[1+c_{\tau}-\frac{l_{\tau}^{\omega}}{\omega}\right]^{-\beta}, \quad \beta>0
$$

where $\beta$ captures the elasticity of the discount factor with respect to the composite $\left(c_{\tau}, l_{\tau}\right)$, $\nu($.$) is bounded away from zero, \nu^{\prime}()>$.0 and $\nu^{\prime \prime}()<$.0 .

As has become standard in the literature on SOEs, the structure of utility and time preference were chosen to provide stable and reasonable dynamic behavior in this economy. As pointed out by Obstfeld and Rogoff (1996), incorporating an endogenous rate of time preference is one medium ${ }^{5}$ for ensuring that a SOE will avoid the "knife-edge" or non-stationary

\footnotetext{
${ }^{4}$ Not surprisingly, there has been no consensus in the macroeconomic literature on the use of an endogenous rate of time preference. However, if a constant subjective time preference factor can be considered as a special case of a variable time preference, then one can invariably conceive of the constant discount factor as being nested within this more flexible-time-preference framework. Thus, the results obtained from this more general specification will be consistent with those generated from the more restrictive constant time preference model. Moreover, Schmitt-Grohé and Uribe (2003) has shown that while modifications to the standard economy model are necessary to ensure stationary in an open economy framework, the choice of modification is irrelevant as the results are unaffected by the choice.

${ }^{5}$ Other ways of ensuring stationarity in a small open economy model include the use of a debt-elastic interest rate premium on the cost of borrowing by local residents or including a convex portfolio adjustment cost.
} 
behavior that will exist under an otherwise standard constant rate of time preference framework. That is, with a constant discount factor, say $\beta^{*}$, the consumption and foreign asset holdings of a SOE will either grow forever if $\beta^{*}>\frac{1}{\left(1+r^{*}\right)}$, or shrink forever if $\beta^{*}<\frac{1}{\left(1+r^{*}\right)}$, thereby making model dynamics dependent on initial conditions. Moreover, the second moments for consumption and foreign asset holdings will be undefined as both series will possess unit roots, thus stationarity can only be assured locally.

An essential feature of this functional of the time preference, therefore, is that agents exhibit increasing marginal impatience towards future consumption. This appealing feature allows for the inter-temporal connection of tastes in a manner that leads to greater impatience towards future consumption in response to any marginal increase in current felicity - thereby leading to a decline in the subjective weight given to all future felicity. We will also require that the functional exhibit a diminishing rate of marginal impatience. This "recursiveness" in the time preference factor will result in the relaxation of the time additivity separable preferences generally assumed, and will allow the marginal utility of consumption for any given period to vary with consumption in any other period.

\subsection{Production Technologies:}

The economy considered produces an internationally tradeable composite consumption commodity and a second period capital good. The production technology for the tradeable consumption good is given by:

$$
F\left(u_{t} k_{t}, l_{t}\right)=z_{t}\left(u_{t} k_{t}\right)^{\alpha} l_{t}^{1-\alpha}-\left(\frac{\phi}{2}\right)\left(k_{t+1}-k_{t}\right)^{2} \quad 0<\alpha<1, \quad \phi>0
$$

where $z_{t}\left(u_{t} k_{t}\right)^{\alpha} l_{t}^{1-\alpha}$ captures the economy's gross domestic product (GDP), with $u_{t}$ representing an index of the endogenous utilization rate of current capital stock, $l_{t}$ being labor hours supplied and $k_{t}$ is the domestic capital stock in period $t$. The parameter $\alpha$ represents the share of gross domestic product that goes to effective capital services, with the remainder being the fraction of income accruing to labor services. In this framework the variable $z_{t}$ represents the transformed realization of exogenous shock to TFP, given by $\varsigma_{t}$. As such, $z_{t}=\gamma_{z}^{t} e^{\varsigma_{t}}$, where $\gamma_{z}$ captures the long-run growth rate of TFP. Following the SOE literature, the function $\left(\frac{\phi}{2}\right)\left(k_{t+1}-k_{t}\right)^{2}$ constitutes the cost of adjusting capital over the period $t$ and $t+1$, and is an increasing function of gross investment. 
Adjustment costs are generally introduced in models of this type as a mechanism for smoothing the reallocation of wealth between physical capital and the foreign asset holdings in response to temporary differentials in the net rate of return between foreign and domestic assets. As a result, the adjustment cost can be seen as the cost(s) associated with the installation of new machinery and equipment. This cost could be considered to include training, installation fees and the cost of disposing of the old stock of machinery. The essential thing to note here, however, is that this cost will act as a moderating force on the investment decision of domestic firms, thereby eliminating excessive responsiveness in investment decisions to small rate differentials, and to ensure that any adjustment to the capital stock is gradual. In this regard, total output in this model economy for period $t$ becomes GDP less the cost of adjusting capital in that period.

The production function for the next period capital stock is given by:

$$
k_{t+1}=\left(1-\delta\left(u_{t}\right)\right) k_{t}+q_{t} i_{t} \quad 0 \leq \delta \leq 1,
$$

with,

$$
\delta\left(u_{t}\right)=\frac{1}{\theta} u_{t}^{\theta}
$$

where $i_{t}$ is gross investment, the non-negative $\delta_{t}$ is the current rate of depreciation, such that $\delta^{\prime}>0$ and $\delta^{\prime \prime}>0$, and $q_{t}$ captures the transformed realization of exogenous shocks to the efficiency of investment goods in the production of next period capital goods given by $\varepsilon_{t}$. As such, $q_{t}=\gamma_{q}^{t} e^{\varepsilon t}$, where $\gamma_{q}$ captures the long-run growth rate in the efficiency of investment goods in the production of next period capital. We can therefore interpret $q_{t}$ as either the productivity of new machinery and equipment in period $t$, which increases overtime or alternatively as the period $t$ relative price of investment goods in terms of consumption goods given by $\pi_{t}=\left(1 / q_{t}\right)$ - as such the relative price declines over time with improvements in the efficiency of investment goods in the production of next period's capital goods.

The representative household has access to a perfectly competitive international capital market where they can trade in international financial assets $a_{t}$ at the exogenously determined risk-free world interest rate $r_{t}^{*}$. As such, $a_{t}$, is the level of foreign assets held by domestic agents. Since we are considering a small open economy, the residents of this economy will face a perfectly elastic supply of this international financial asset, and the accumulation of 
this type of asset will evolve according to the following process:

$$
a_{t+1}=t b_{t}+\left(1+r_{t}^{*}\right) a_{t}
$$

where $t b_{t}$ is the trade balance. This equation states that for balance of payment equilibrium and international capital market solvency, the trade balance on goods and services (given by $t b_{t}$ ), plus interest payment on foreign debt (given by $r_{t}^{*} a_{t}$ ), must equal the change in domestic foreign asset holdings (captured by $a_{t+1}-a_{t}$ ). To prevent agents from playing Ponzi-type games, the following restriction is imposed on the holding of these foreign assets:

$$
\lim _{t \rightarrow \infty} E_{0}\left\{a_{t+1} \frac{1}{\left(1+r_{t}^{*}\right)^{t}}\right\}=0
$$

The aggregate resource constraint ${ }^{6}$ for the domestic economy, then, will dictate that the sum of consumption, gross investment and the trade balance must not exceed the gross domestic product net of adjustment costs. That is:

$$
c_{t}+i_{t}+t b_{t} \leq z_{t}\left(u_{t} k_{t}\right)^{\alpha} l_{t}^{1-\alpha}-\left(\frac{\phi}{2}\right)\left(k_{t+1}-k_{t}\right)^{2}
$$

\subsection{Model Dynamics and Steady State Behavior:}

The household's optimization problem, therefore, becomes the maximization of the utility function given by Eqn. (1) subject to the resource constraint given by Eqn. (9). The solution to this optimization problem will thus result in a sequence of optimal choices for consumption, hours, output, investment, the utilization rate, capital stock and foreign asset holdings, given by $\left\{c_{t}, l_{t}, y_{t}, i_{t}, u_{t}, k_{t+1}, a_{t+1}\right\}_{t=0}^{\infty}$ for the representative agent.

To fully appreciate the dynamics at work in this model, consider the following first order condition with respect to consumption:

$$
u_{1}\left(c_{t}, l_{t}\right)-v_{1}\left(c_{t}, l_{t}\right) E_{t} \sum_{s=t+1}^{\infty} u\left(c_{s}, l_{s}\right) \exp \left[-\sum_{z=1}^{s-1} v\left(c_{z}, l_{z}\right)\right]-\lambda_{t}=0
$$

where $u_{1}\left(c_{t}, l_{t}\right)=\left[c_{t}-\frac{l_{t}^{\omega}}{\omega}\right]^{-\gamma}$ and $v_{1}\left(c_{t}, l_{t}\right)=\beta\left[1+c_{t}-\frac{l_{t}^{\omega}}{\omega}\right]^{-(1+\beta)}$

\footnotetext{
${ }^{6}$ Alternatively, the resource constraint can be expressed as $c_{t}+\pi_{t} i_{t}+t b_{t} \leq z_{t}\left(u_{t} k_{t}\right)^{\alpha} l_{t}^{1-\alpha}-\left(\frac{\phi}{2}\right)\left(k_{t+1}-k_{t}\right)^{2}$, where $\pi_{t}$ captures the exogenous innovations to the price of investment goods relative to consumption goods, thereby obviating the need for shocks to the efficiency of investment, which is captured by the $q_{t}$ representation in the capital accumulation Eqn. (5) .
} 
This representation of the FOC with respect to consumption differs considerably from the standard equation generated from the constant time preference framework, in that Eqn. (10) equates the marginal utility of consumption in period $t$ - a positive quantity - to some shadow price $\lambda_{t}$ (the marginal utility of wealth). More importantly, the marginal utility of consumption today can be seen as the sum of two components, the first term is the increase in today's felicity from an increase in today's consumption $c_{t}$, and the second term is the indirect loss in felicity that is endured from waiting - or the discounted value of tomorrow's felicity. Under the assumption that the marginal rate of impatience is declining, this value will always be positive. In steady state - with constant consumption flows - the second term will disappear as the subjective discount factor will be a constant, $v_{1}\left(c_{t}, l_{t}\right)=0$. With $v_{1}\left(c_{t}, l_{t}\right)>0$, the model predicts that higher consumption today will lower the marginal utility of consumption on successive dates.

More importantly, the preference structure implies that the marginal rate of substitution between dates $t$ and $t+1$ is entirely independent of consumption levels before period $t$, but not independent of consumption after period $t+1$. This will therefore give rise to the variability in the rate of time preference in a manner that will ensure that the SOE will converge back to some steady state after any shock to the world interest rate. With this model configuration, the first order conditions for next period's foreign asset and capital holdings will be given by:

$$
-\lambda_{t}+\exp \left[-\sum_{\tau=0}^{t-1} v\left(c_{\tau}, l_{\tau}\right)\right] E_{t}\left[\lambda_{t+1}\left(1+r_{t+1}^{*}\right)\right]=0
$$

and

$-\lambda_{t}\left[\frac{1}{q_{t}}+\phi\left(k_{t+1}-k_{t}\right)\right]+\exp \left[-\sum_{\tau=0}^{t-1} v\left(c_{\tau}, l_{\tau}\right)\right] E_{t}\left[\lambda_{t+1}\left(\frac{\left(1-\delta\left(u_{t}\right)\right)}{q_{t+1}} \alpha\left(\frac{y_{t+1}}{k_{t+1}}\right)+\phi\left(k_{t+2}-k_{t+1}\right)\right)\right]=0$

Similarly, the optimal allocation of labor hours and the endogenous rate of capital utilization are governed by the following first-order equations:

$$
u_{2}\left(c_{t}, l_{t}\right)-v_{2}\left(c_{t}, l_{t}\right) E_{t} \sum_{s=t+1}^{\infty} u\left(c_{s}, l_{s}\right) \exp \left[-\sum_{z=1}^{s-1} v\left(c_{z}, l_{z}\right)\right]+\lambda_{t}(1-\alpha) \frac{y_{t}}{l_{t}}=0
$$

and

$$
\alpha \frac{y_{t}}{u_{t}}-\delta^{\prime}\left(u_{t}\right) k_{t}=0
$$

where $u_{2}\left(c_{t}, l_{t}\right)=-\left[c_{t}-\frac{l_{t}^{\omega}}{\omega}\right]^{-\gamma} l^{\omega-1}, v_{2}\left(c_{t}, l_{t}\right)=-\beta\left[1+c_{t}-\frac{l_{t}^{\omega}}{\omega}\right]^{-(1+\beta)} l^{\omega-1}$, and $\delta^{\prime}\left(u_{t}\right)=u_{t}^{\theta-1}$. 
This result is particularly important since it infers that the marginal rate of substitution between consumption and labor will depend on labor only. And thus labor choice will be determined independently of the inter-temporal consumption-savings decision. Moreover, this structure also affords us the luxury of attributing all variations in labor supply to the wealth effect of the shock under consideration.

Despite the endogenous nature of the rate of time preference, and due to the functional forms adopted, the equations of the optimal solutions will confer the same steady state solutions as those that will be obtained with constant rate of time preference or a constant discount factor. This outcome is particularly important since it allows the constant time preference framework to be nested in this more general model specification.

\subsection{Calibration and Simulation Method:}

The calibrated values used in this analysis are those provided by Mendoza (1991); whose calibrated results were generated by matching key moments of Canadian macroeconomic series. The following are the values assigned to the structural parameters ${ }^{7}$ used in this paper:

$$
\alpha=0.32, \quad r^{*}=0.04, \quad \gamma=2.0, \quad \delta=0.10, \quad \omega=1.455, \quad \beta=0.11135, \quad \theta=1.42
$$

where $\alpha$ is the share of GDP allocated to capital services, $r^{*}$ is the steady state world interest rate - determined exogenously on the world financial market, $\gamma$ is the coefficient of relative risk aversion, $\delta$ is the steady state depreciation rate, $\omega$ is 1 plus the inverse of the inter-temporal elasticity of substitution of labor supply, $\beta$ is the elasticity of the rate of time preference with respect to current utility, and $\theta$ captures the elasticity of depreciation with respect to utilization $^{8}$.

The competitive equilibrium allocations for this model is then a set for consumption, hours, output, investment, utilization and next period's capital and foreign asset holdings, $\left\{c_{t}, l_{t}, y_{t}\right.$, $\left.i_{t}, u_{t}, k_{t+1}, a_{t+1}\right\}_{t=0}^{\infty}$, respectively, given the state of the economy in each period - which satisfies the optimal equations described earlier.

\footnotetext{
${ }^{7}$ Mendoza (1991) for an extensive discussion on the generation of these calibrated parameter values.

${ }^{8}$ This value comes from Greenwood et al. (1988), and was chosen so that the steady state depreciation rate is $10 \%$.
} 
For this model specification, as is evident by the dependence of the first order conditions on an infinite sequence of consumption and labor streams, the competitive equilibrium allocations do not have closed-form analytical solutions. Thus the model must be solved numerically. To achieve this, the problem will be solved as a social planning problem - for which the Welfare Theorems apply. This will be done by finding an approximate solution to the log-linear approximation of the first order conditions about their steady-state values. The approach used here is the method advocated by Greenwood et al. (1988) and is similar to that used by Schmitt-Grohé and Uribe (2003). The moments used in this analysis are the percentage standard deviation, the first-order autocorrelation of each variable of interest and their respective first-order serial correlation with output.

To close the model setup the propagation mechanisms for investment-specific technology and total factor productivity shocks considered in this economy are described by the following processes:

$$
\ln q_{t}=\alpha_{q}+t \ln \gamma_{q}+\eta_{t}^{q}
$$

and,

$$
\ln z_{t}=\alpha_{z}+t \ln \gamma_{z}+\eta_{t}^{z}
$$

where

$$
\eta_{t}^{i}=\rho_{i} \eta_{t-1}^{i}+\xi_{t}^{i}
$$

Where $\alpha_{i}$ is a regression constant, $0<\rho_{i}<1$ describes the persistence of each shock, $\gamma_{i}$ captures the trend component of each process, and $\xi_{t}^{i} \sim N\left(0, \sigma_{i}\right)$, for $i \in\{z, q\}$. The relevant parameter values for $\sigma_{z}, \sigma_{q}, \rho_{z}$, and $\rho_{q}$ defining the asymptotic standard deviation and the first-order serial correlation for the TFP and IST were estimated directly by running the respective regression equations for the two driving processes given by Eqn. (15)- (16) using Canadian data. ${ }^{9}$ This direct estimation procedure offers the advantage that the stochastic processes used in this analysis are directly identified by the data and so greater confidence can be gained from the simulation exercises conducted. ${ }^{10}$

For analytical purposes the stochastic processes considered are assumed to be uncorrelated to each other. By doing this, we will be able to isolate the respective contribution of each

\footnotetext{
${ }^{9}$ The regression estimates for these parameters are provided in Table 5.

${ }^{10}$ This approach, differs considerably from that of Mendoza (1991), and Schmitt-Grohé and Uribe (2003), where the values for $\sigma_{z}, \rho_{z}$ and $\phi$ were chosen to match the variability and first-order autocorrelation of GDP.
} 
shock considered to macroeconomic fluctuation in the economy, without having to account for the the contribution made by any other exogenous propagation facing the economy. As a result of this orthogonality assumption, to generate the requisite moments and the associated impulse responses, the model was simulated separately for 400 periods in response to a $1.0 \%$ temporary shock to TFP and IST (or equivalently a $-1.0 \%$ shock to the relative price of investment goods). This simplification of the driving process is particularly important since it will ensure that the results generated from the two innovations are comparable in dimension.

Given the parameter values for the stochastic processes described above, the only remaining parameter to be determined in this model will be $\phi$ - the capital adjustment parameter. This parameter is particularly important since it determines (to a large extent) the investment response to innovations to the exogenous processes considered. As discuss earlier, in this small open economy framework adjustment costs are introduced to moderate the investment response to differential between the net return on domestic capital and the world interest rate (the rate of return on foreign assets). Despite its significance, however, this parameter cannot be determined ex ante as it has no empirical counterpart. In light of this fact, to obtain the requisite value for this parameter the model was simulated to match the percentage standard deviation of investment found in the data.

\section{Simulation Results:}

This section is primarily aimed at comparing the performance of the two measures of productivity innovations under consideration - namely shocks to total factor productivity (TFP) and investment specific technology (IST). To do this, particular attention will be paid to the ability of the two propagation mechanisms to match key moments in the Canadian data. That is, we shall examine the percentage standard deviation (volatility) and first-order autocorrelation of output, consumption, labor supply, investment, the current account to output ratio $(\mathrm{CA} / \mathrm{Y})$, and the ratio of the trade balance to output $(\mathrm{TB} / \mathrm{Y})$. Attention will also be paid to their respective first-order serial correlation with output. Further analysis will be conducted by examining the associated dynamics of these variables of interest by studying the impulse responses generated from the two propagations considered.

The analysis to follow will be divided into two sections, with the first one looking at the 
benchmark model where the capital utilization rate will be treated as constant. Attention will then be given to a more elaborate model setup in which firms would be allowed to vary their capital utilization rate endogenously in response to the two exogenous propagations.

\subsection{The Benchmark Model:}

As stated, the benchmark model examined here refers to a setup in which the capital utilization rate and hence the depreciation rate of the model will be treated as constant and equal to their respective steady state values. In this regard, one can easily assess the impact of innovations to investment-specific technology and total factor productivity on the model under review, since all other endogenous propagation has been eliminated.

The requisite moments generated from the simulation exercises are presented in Table 1 below. Column 2 of Table 1 refers to the associated moments observed in the Canadian data (1961-2003). ${ }^{11}$ Columns $3 \& 4$ refer to moments generated from shocks to TFP and IST, respectively.

As can be seen from Table 1, where the ability of the two models to mimic key moments in the data is compared, both models perform unsatisfactorily in matching the corresponding statistics observed in the Canadian data. In particular, in both models the volatility and first-order autocorrelation statistics of the variables of interest are larger than those observed in the data - and in some cases these estimates are significantly larger. For example, in the model with the TFP shocks, the volatility of GDP is almost four times that observed in Canada, while the volatility of consumption is almost six times the standard deviation of consumption in the data. Comparatively, in the IST shocks framework the volatility of output and consumption are approximately twice the size of their empirical counterparts. In addition to these failures, two other striking observations can be made from the evidence provided from the two models.

Firstly, in the TFP shock model setup the ranking of the volatility of consumption and output departs from its counterpart in the data. That is, in this model specification consumption is more volatile that output - a result that deviates from the data where the ranking is reversed. This key disparity with the data is significant since it means that in an open econ-

\footnotetext{
${ }^{11}$ See the Appendix for a description of the data used.
} 
omy where there is trade in international financial assets, when investment volatility in the model is matched to that in the data, all the volatilities generated from the trade in international financial assets are directly transferred to the consumption decisions of agents in this model economy. This anomaly, however, does not occur under the IST-shocks framework. As such, in this dimension it is apparent that the the IST-shocks model outperforms the model with shocks to TFP.

Secondly, it is evident that all the variables considered generate pro-cyclical responses to innovations to total factor productivity and investment efficiency. Of particular interest though is the failure of the two models to generate the counter-cyclical responses in the CA/Y and $\mathrm{TB} / \mathrm{Y}$ ratios that have generally been the feature of most international business cycle models. In the case of the IST shocks model, this is entirely due to the lack of endogenous propagation in the model, an issue that will become apparent when the impulse responses are discussed below. One other difference that stands out among the two model specifications is that when the economy is subjected to IST-shock the correlation between investment and output is half that in the TFP-shock framework.

Despite having second moments that are somewhat similar, it becomes apparent by looking at the respective impulse responses for the TFP and IST shocks models provided in Figure 2 and Figure 3 respectively, that the dynamic behavior of the model economy under the two propagating mechanisms are considerably different. In fact, in both models the dynamic path taken by the variables considered differs appreciably. This outcome is not entirely surprising since the nature and initial impact of the two innovations under consideration are different. It is quite evident that the lack of wealth effect in the first period from the IST-shocks contributes significantly to these differences in the initial periods.

For example, in the case of the standard TFPs-shock, current output (and hence the marginal productivity of labor and current capital) will be affected immediately and directly, in which case firms respond by increasing the amount of labor allocation in the first period of impact, thereby generating the immediate increase in current output. On the other hand, in the case of the investment-specific shock model the response is much more delayed as the marginal productivity of labor and current capital are not directly affected in the first period, thus there will be no first period response in these variables. Hence the sluggish response of output. Indeed, changes in labor and capital decisions will only occur in the second periods 
onwards and the response of labor supply will be more sluggish than is generally the case. This sluggish response explains the hump-shape dynamic path in output, consumption and labor supply in the IST-shocks model compared to the TFP-shocks model, while the dynamic path for investment and hence capital stock is similar.

To fully understand the differences observed in the correlation between investment and output for these models, however, one must then look at the respective dynamic path for output. For the benchmark model output rises by roughly $2 \%$ in the first period of impact before declining to its steady-state value, a considerably faster response than that experienced in the Investment-specific shock models where the impulse response was much more delayed and prolonged. More interestingly, the low correlation between investment and output observed in the models with RP-shocks becomes obvious when it is observed that the gradual increase in output was associated with the steady decline in investment. The obvious conclusion here then is that the omission of the direct propagation from the exogenous shock facing the economy to output dampens the extent to which the moments generated can match those observed in the data.

Further insights can then be gained into the dynamic behavior of the two models by considering the dynamic path for foreign assets holdings. Given that the economy is a net debtor in steady-state (interest payment is set at $2 \%$ of GDP), by restraining the investment decision of agents such that volatility of investment matches that in the data the response of agents in the two model is appreciably different. This is evident by an almost $6 \%$ reduction in foreign debt holdings of domestic residents in response to shocks to TFP as local residents attempt to take advantage of the opportunity provided by the increase productivity of capital and labor to reduce their foreign debt holding. In fact, in the TFP-shocks model compared to the more modest increase of $1.7 \%$ observed for the IST shocks case. However, with a shock to RP there is a considerable undershooting of the foreign debt position, a phenomenon that is not observed when shocks to total factor productivity are considered. The other impulse responses provided are for the trade balance to GDP (TB/Y), the current account to GDP $(\mathrm{CA} / \mathrm{Y})$ and the capital stock. In all of these cases the impulse responses generated are opposite for both types of model setup.

The conclusion that can then be drawn from this analysis is that when shocks to total factor productivity and investment-specific technology are considered the model behavior 
is generally consistent with the predictions of the neoclassical macroeconomic theory. A significant failure of this model framework, however, is its inability to mimic the negative correlation between the $\mathrm{CA} / \mathrm{Y}$ and $\mathrm{TB} / \mathrm{Y}$ ratios and output observed in the data. Finally, these models provide volatility statistics for output, consumption and labor supply that are higher than their empirical counterparts. In particular, the models generated volatility of output that were considerably higher than those seen in the data and produce a positive correlation between output and the CA/Y and TB/Y ratios. While these shortcomings appear to reduce the premise that IST shock are important determinants of business cycle behavior in small open economies, there are avenues through which the model can be modified to provide more reasonable business cycle behavior. Principal among these is the incorporation of an endogenous capital utilization rate - which will be considered next.

\subsection{Model with Endogenous Capital Utilization Rate:}

In this section, attention is given to the same two propagations considered earlier with the only difference being the inclusion of an endogenous rate of capital utilization to the model economy. The addition of a variable capital utilization rate to the model is principally aimed at providing the previously missing direct link between the innovations considered and current output by increasing the effective capital supply in the first period through increased utilization of the capital stock. More importantly, this augmentation of the model will be expected to provide improvements to the anomalous correlation between the ratios of $\mathrm{CA} / \mathrm{Y}$ and $\mathrm{TB} / \mathrm{Y}$ and output reported earlier - a significant failure observed in the benchmark model.

In order to do this, however, the parameter estimates for the TFP propagation mechanism will invariably change. That is, given that the endogenous utilization rate variable is posited inside the production function for the composite consumption good, the estimate of the Solow residuals will be directly affected. The new estimates for these parameters are provided

in Table 5, where the regression estimates of the TFP-shocks are now more volatile and less persistent than in the benchmark case. Table 2 below provides the requisite moments generated from the new simulation exercises. As before, the reported moments were generated by matching the volatility of investment seen in the Canadian data. In the case of the TFP-shocks, however, the volatility of investment could not be matched exactly and thus an 
estimate of $\phi$ equivalent to ten times that used in the benchmark model was used. Given the unfavorable outcome of the TFP-model to this specification a further sensitivity analysis was subsequently conducted.

As is evident from Table 2, both models were able to obtain volatilities for the external accounts and labor that are much closer to their empirical counterparts. More importantly, however, it becomes obvious that the IST-shocks model outperforms the TFP-shocks setup as the improvement in the correlation between the ratios of $\mathrm{CA} / \mathrm{Y}$ and $\mathrm{TB} / \mathrm{Y}$ and output was achieved only in this framework when augmented with the endogenous utilization rate. This improvement is due entirely to the fact that the inclusion of the endogenous utilization rate resulted in a faster and larger increase in output than previously observed, and thus the increased productivity in capital engenders the faster accumulation in foreign debt.

In fact, as seen by the impulse responses displayed in Figure 4 and Figure 5, the increase in output is twice that achieved in the previous setup in both models - with close to $0.6 \%$ increase in the first period of impact in the case of the model with IST-shocks and 3\% in the TFP-shocks model, before declining back to steady-state. Moreover, the impulse responses show that in both cases the utilization rate of capital increases above its steady state level in the first period by just over $1.5 \%$ in the case of the IST-shocks and by $2 \%$ in the case of the TFP-shocks, thereby igniting the increase in output seen. This augmentation of the model also ensures that the perfect correlation between labor supply and output previously reported in Table 1 has been eliminated in a manner that makes it more consistent with the data.

As also documented by the impulse responses shown, the response of investment and foreign debt holdings to the exogenous propagations are quite significant. In the case of investment, agents respond by increasing their current investment by over $3 \%$ in the case of TFP-shocks and $1.5 \%$ in the IST-shocks setup, while foreign debt increases by as much as $0.7 \%$ in the IST-shocks model, but falls by as much as $1.4 \%$ in the TFP-shocks setup. The reason for these apparent strong responses is basically because of the higher return to capital that results from the exogenous propagations. These responses, however, were mitigated by the increased adjustment cost incorporated in the model. One noteworthy observation that can be made is that in this framework the impulse responses from both propagations are somewhat similar. That is, despite the difference in second moments, in most cases the dynamic path of the variables in both model are considerably similar. 


\subsection{Sensitivity Analysis with respect to $\phi$ :}

It is important to note that in the IST shocks framework, to moderate the response of investment, the value for the adjustment cost parameter $\phi$ used was ten times that used in the benchmark case. On the other hand, in the TFP-shocks model there is the surprising outcome that in this framework the volatility of investment could not be moderated to match the value observed in the data. Indeed, despite a value of adjustment cost equal to ten-times that used in the benchmark model, it is evident that the volatility of investment is still higher than its empirical counterpart when the model is augmented with an endogenous utilization rate. Moreover, the failure of the TFP-shocks model to match the counter-cyclical behavior of the external account variables in the data may in fact be the result of the high value of $\phi$ used.

As a further check of the sensitivity of the results to the inclusion of the endogenous utilization rate, the new model was simulated with the exact parameter values used in the benchmark model (as given in Table 5 of the Appendix). The purpose of this exercise was to ascertain the extent to which the inclusion of an endogenous capital utilization rate, ceteris paribus, affects the performance of the model in matching the moments observed in the Canadian data. The results from this exercise are presented in Table 3. As is evident in that table, TFP-shocks model requires an artificially low value for the adjustment parameter in order to generate the counter-cyclical behavior in the data. In addition, with these parameter values, the model provides volatility statistics for all variables - especially investment, that are vastly exaggerated. As expected, in the case of the IST-shocks model the volatility of the variables considered increase substantially with the external accounts still remaining counter-cyclical.

The conclusion that can be made from this model extension is that the inclusion of an endogenous utilization rate provides unambiguous improvements in the performance of the IST-shocks model, while the performance of the TFP-shocks model is sensitive to the parameter values used in the analysis. This sensitive behavior of the TFP-shocks model is not entirely surprising, since Letendre (2004) found that when his baseline model was augmented with an endogenous utilization rate it necessitated the use of a propagation to the exogenous TFP-shocks that was seventeen percent smaller than in the baseline model in order for the model to provide reasonable moments. In this regard, one can easily conclude that the 
IST-shocks model outperforms the TFP-shocks model.

\section{Conclusion and Extensions:}

The model considered provides a novel starting point for looking at the impact of innovations to investment-specific technology, captured by shocks to the relative price of investment goods on a small open economy. Of particular interest in this paper has been the ability of shocks to IST to provide macroeconomic fluctuations in a small open economy that are generally consistent with neoclassical economic predictions. As with the standard TFP-shocks model, shocks to IST were able to generate significant macroeconomic fluctuations in the small open economy considered and outperforms the standard TFP-shocks in matching unconditional moments in the Canadian data.

Most significantly, the model was able to generate the counter-cyclical behavior of the external accounts when the model was augmented with an endogenous utilization rate without appealing to an adjustment cost parameter and/or a propagation mechanism whose volatility and persistence that are artificially low. This contrasts significantly with the TFP-shocks model in which the external accounts remains pro-cyclical, contrary to the empirical evidence. In fact, the conjecture that the standard TFP-shocks model requires an artificially low value for the adjustment parameter to generate the counter-cyclical movement in the external account has been confirmed.

Notwithstanding, some apparent deficiencies of this model specification, namely the exaggeration of the volatility of output, the basic framework adopted here offers some interesting insights into the associated dynamics that are generated from a unit shock to IST. These insights are exemplified by the observation that the model predicts that in a small open economy framework, shocks to IST have similar impact on the overall macro-economy and generate

similar dynamic responses as shocks to the world interest rate. This perceived similarity is particularly interesting since it provides a new dimension for looking at SOE dynamics. 


\section{References}

Baxter, M. (1995). International trade and business cycles. In Grossman, G. M. and Rogoff, K. S., editors, Handbook of International Economics, volume 3, pages 1801-1864. NorthHolland, Amsterdam.

Boileau, M. (2002). Trade in capital goods and investment-specific technical change. Journal of Economic Dynamics and Control, 26:963-984.

Epstein, L. and Hynes, A. (1983). The rate of time preference and dynamic economic analysis. Journal of Political Economy, 91:611-625.

Fisher, J. D. M. (1999). The new view on growth and business cycles. Economic Perspectives, $23(1): 34-56$.

Fisher, J. D. M. (2003). Technology shocks matter. Federal Reserve Bank of Chicago, WP02-14.

Greenwood, J., Hercowitz, Z., and Huffman, G. W. (1988). Investment capacity utilization, and the real business cycle. The American Economic Review, 78:402-417.

Greenwood, J., Hercowitz, Z., and Krusell, P. (1997). Long run implications of investmentspecific technological change. The American Economic Review, 87:342-362.

Greenwood, J., Hercowitz, Z., and Krusell, P. (2000). The role of investment-specific technological change in the business cycle. The European Economic Review, 44:91-115.

Keynes, J. M. (1936). The General Theory of Employment, Interest and Money. Macmillan, London.

Letendre, M.-A. (2004). Capital utilization and habit formation in a small open economy. The Canadian Journal of Economics, 37:721-741.

Letendre, M.-A. and Luo, D. (2005). Investment-specific shocks and external balances in a small open economy model. McMaster University, Mimeo.

Mendoza, E. G. (1991). Real business cycles in small open economy. The American Economic Review, 81:797-818. 
Obstfeld, M. and Rogoff, K. (1996). Foundations of International Economics. MIT Press, Cambridge.

Schmitt-Grohé, S. and Uribe, M. (2003). Closing the small open economy model. Journal of International Economics, 61:163-185. 
Table 1: Observed and Simulated Moments for Benchmark Model

Data: TFP Shocks: IST Shocks:

\section{Volatilities:}

$\begin{array}{llll}\text { GDP } & 2.0661 & 7.4901 & 3.4559 \\ \text { Consumption } & 1.3394 & 7.7110 & 2.9620 \\ \text { Investment } & 6.1302 & 6.1302 & 6.1302 \\ \text { Hours } & 0.7582 & 5.1478 & 2.3752 \\ \text { TB/Y Ratio } & 0.3310 & 1.8328 & 1.4986 \\ \text { CA/Y Ratio } & 0.0473 & 1.2143 & 1.4442\end{array}$

Serial correlations:

\begin{tabular}{lccl} 
GDP & 0.6288 & 0.9150 & 0.9875 \\
Consumption & 0.7602 & 0.9443 & 0.9917 \\
Investment & 0.6343 & 0.8634 & 0.7864 \\
Hours & 0.6525 & 0.9150 & 0.9875 \\
TB/Y Ratio & 0.6088 & 0.9797 & 0.7089 \\
CA/Y Ratio & 0.3298 & 0.9404 & 0.6967 \\
Correlation with GDP: & & & \\
GDP & 1.0000 & 1.0000 & 1.0000 \\
Consumption & 0.7339 & 0.9434 & 0.9766 \\
Investment & 0.8193 & 0.9731 & 0.4908 \\
Hours & 0.6521 & 1.0000 & 1.0000 \\
TB/Y Ratio & -0.2445 & 0.2784 & 0.3505 \\
CA/Y Ratio & -0.1185 & 0.9252 & 0.2731 \\
\hline
\end{tabular}

Notes: The first column refers to annual per capita Canadian data that have been logged (with the exception of the trade balance-output and current account-output ratios), and detrended using the HP filter with smoothing parameter $\lambda=100$, before computing the moments. The volatility statistics refer to the percentage standard deviation of the variable of interest. 
Figure 1: Plot of the Data Series for Investment and the RPI in Canada
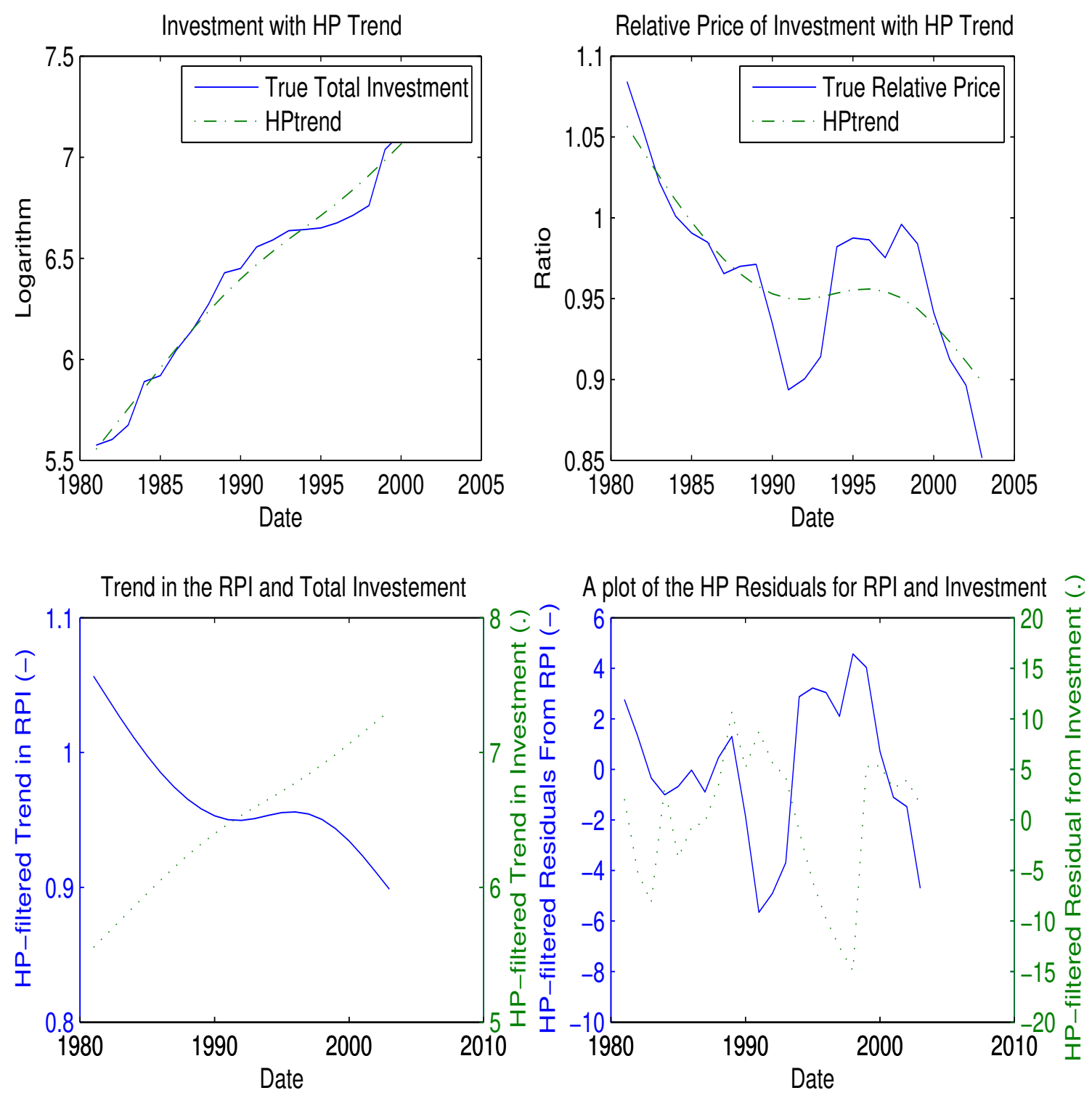
Figure 2: Impulse Response to a Unit TFP Shock
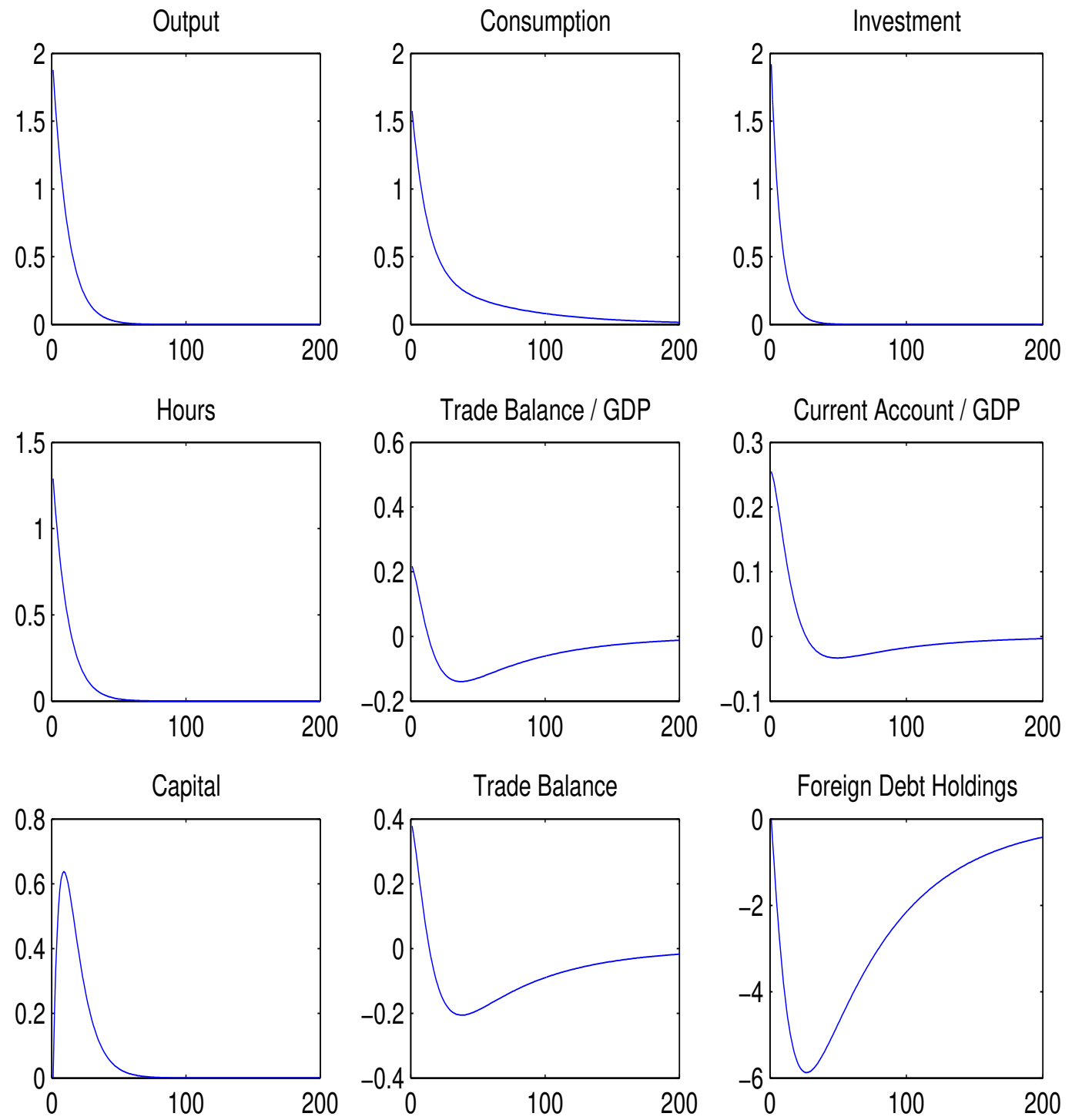
Figure 3: Impulse Response to a Unit IST Shock
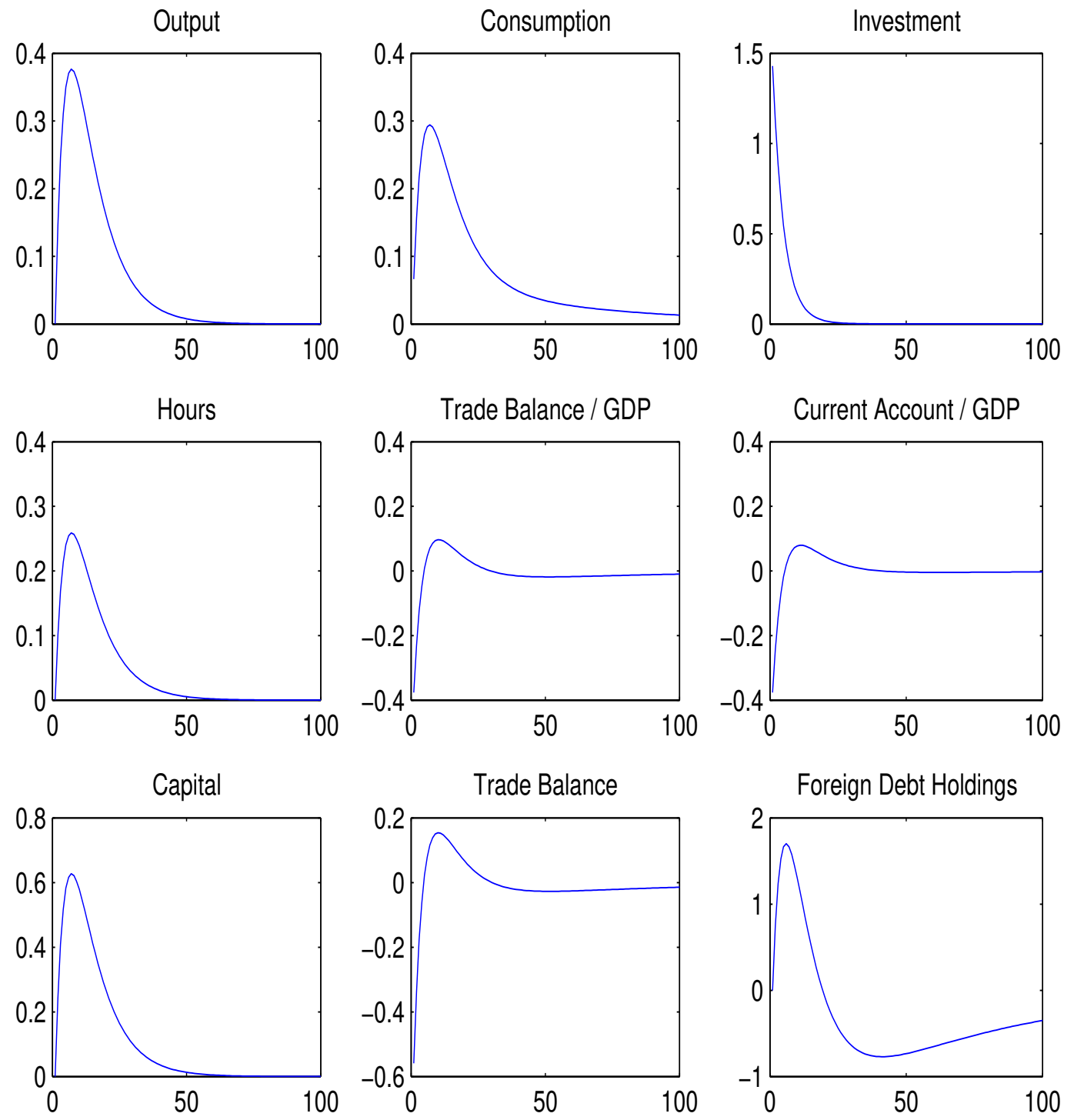
Figure 4: Response to a Unit TFP Shock with Endogenous Utilization
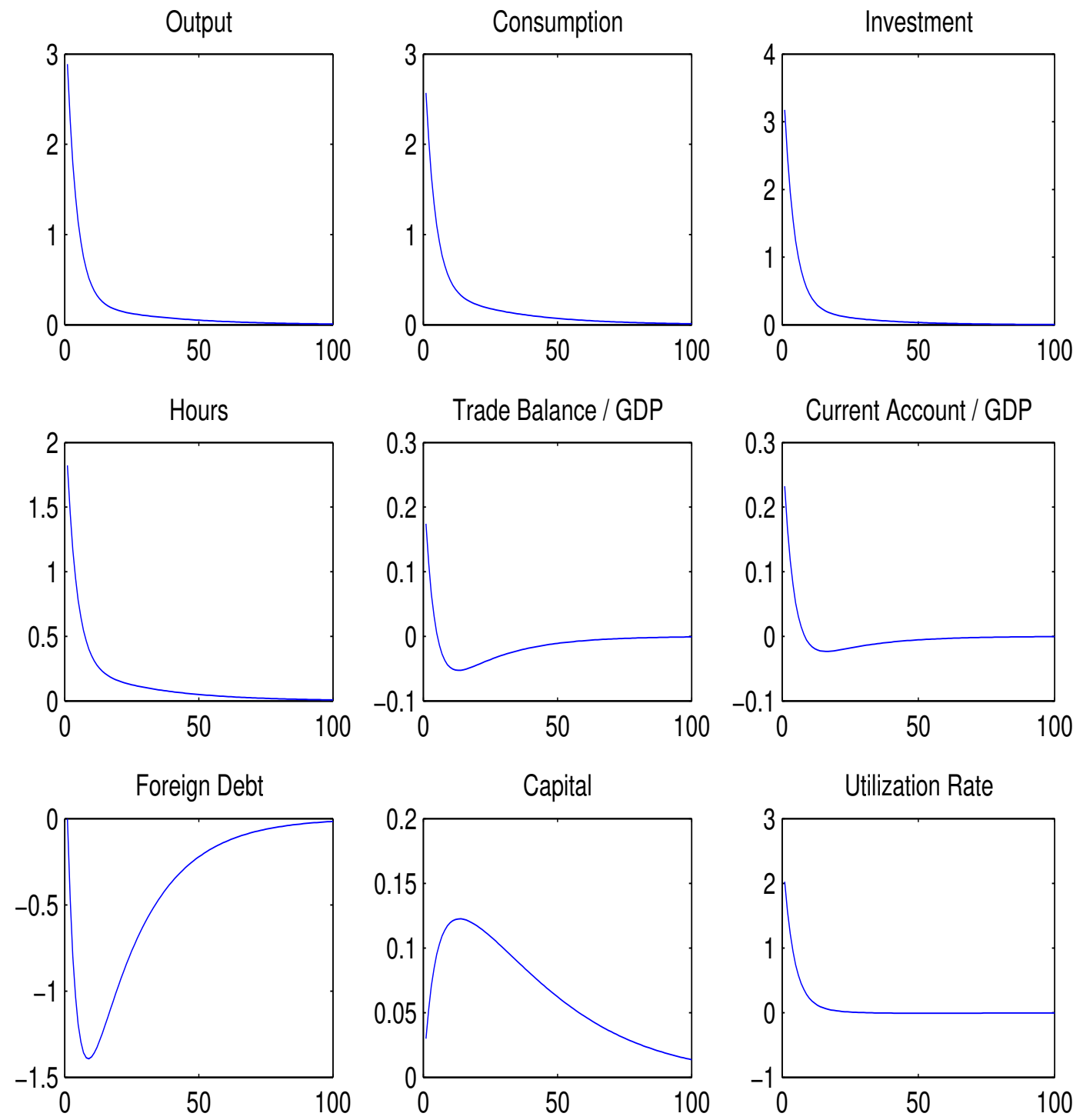
Figure 5: Response to a Unit Shock to IST With Endogenous Utilization
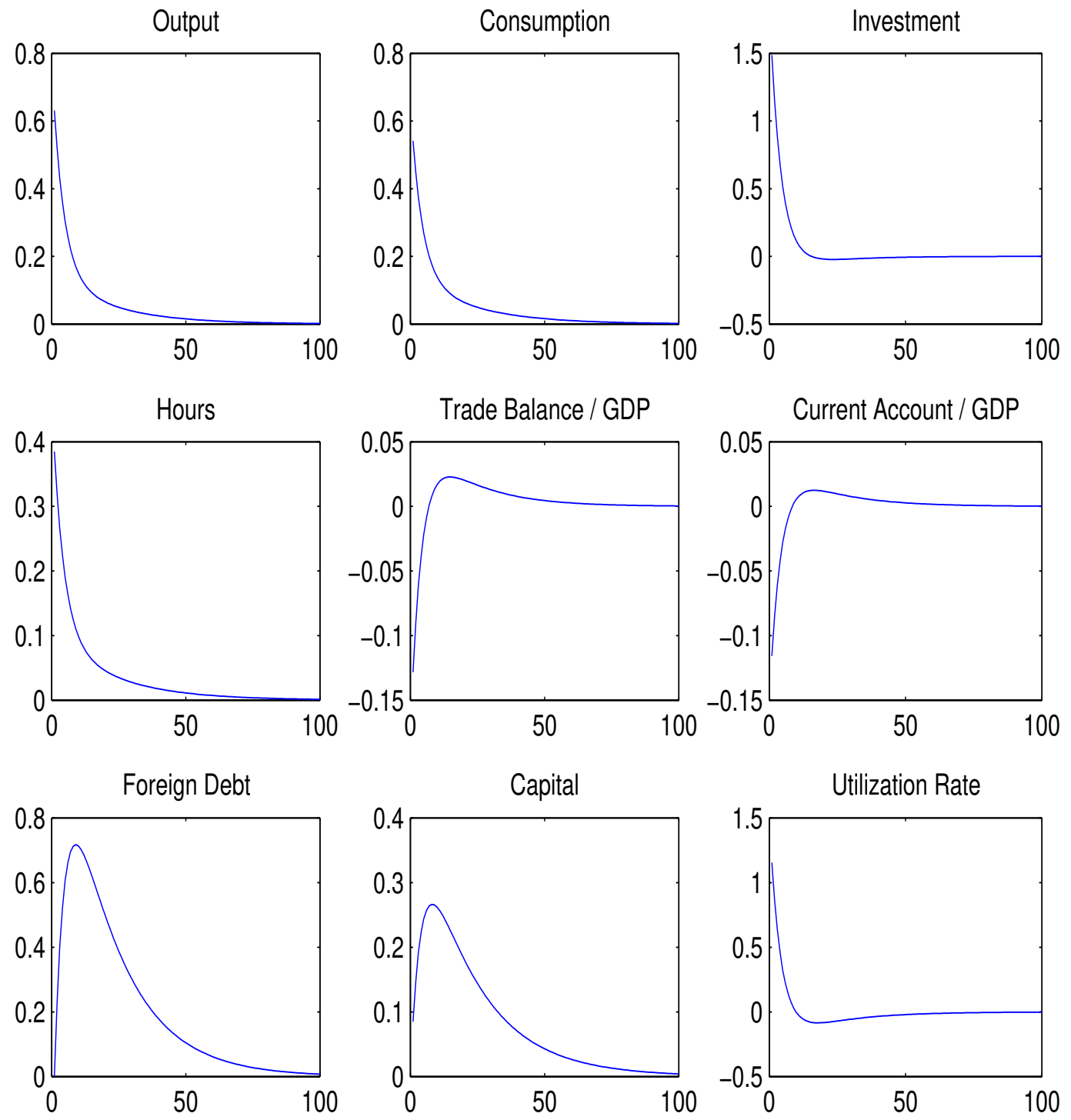
Table 2: Observed and Simulated Moments for Endogenous Utilization Model

Data: TFP Shocks: IST Shocks:

\section{Volatilities:}

$\begin{array}{llll}\text { GDP } & 2.0661 & 8.3778 & 3.1457 \\ \text { Consumption } & 1.3394 & 7.8912 & 2.7768 \\ \text { Investment } & 6.1302 & 9.1151 & 6.1302 \\ \text { Hours } & 0.7582 & 5.5898 & 1.9715 \\ \text { TB/Y Ratio } & 0.3310 & 0.5516 & 0.5285 \\ \text { CA/Y Ratio } & 0.0473 & 0.5923 & 0.4583\end{array}$

Serial correlations:

\begin{tabular}{lccc} 
GDP & 0.6288 & 0.7996 & 0.8465 \\
Consumption & 0.7602 & 0.8231 & 0.8555 \\
Investment & 0.6343 & 0.7952 & 0.7660 \\
Hours & 0.6525 & 0.8223 & 0.8552 \\
TB/Y Ratio & 0.6088 & 0.8056 & 0.7490 \\
CA/Y Ratio & 0.3298 & 0.7247 & 0.7362 \\
Correlation with GDP: & & & \\
GDP & 1.0000 & 1.0000 & 1.0000 \\
Consumption & 0.7339 & 0.9954 & 0.9992 \\
Investment & 0.8193 & 0.9993 & 0.9314 \\
Hours & 0.6521 & 0.9957 & 0.9993 \\
TB/Y Ratio & -0.2445 & 0.4102 & -0.5813 \\
CA/Y Ratio & -0.1185 & 0.8388 & -0.7505 \\
\hline
\end{tabular}

Notes: The first column refers to annual per capita Canadian data that have been logged (with the exception of the trade balance-output and current account-output ratios), and detrended using the HP filter with smoothing parameter $\lambda=100$, before computing the moments. The volatility statistics refers to the percentage standard deviation of the variable of interest. 
Table 3: Observed and Simulated Moments for Sensitivity Analysis

\section{Data: TFP Shocks: IST Shocks:}

\section{Volatilities:}

$\begin{array}{lccc}\text { GDP } & 2.0661 & 10.5671 & 3.9628 \\ \text { Consumption } & 1.3394 & 9.9668 & 3.0578 \\ \text { Investment } & 6.1302 & 15.5179 & 19.8344 \\ \text { Hours } & 0.7582 & 7.0603 & 2.1818 \\ \text { TB/Y Ratio } & 0.3310 & 0.9345 & 3.8605 \\ \text { CA/Y Ratio } & 0.0473 & 0.8132 & 3.6861\end{array}$

Serial correlations:

\begin{tabular}{lccc} 
GDP & 0.6288 & 0.8938 & 0.9230 \\
Consumption & 0.7602 & 0.9030 & 0.9213 \\
Investment & 0.6343 & 0.8119 & 0.6664 \\
Hours & 0.6525 & 0.9027 & 0.9213 \\
TB/Y Ratio & 0.6088 & 0.7068 & 0.6681 \\
CA/Y Ratio & 0.3298 & 0.7191 & 0.6569 \\
Correlation with GDP: & & & \\
GDP & 1.0000 & 1.0000 & 1.0000 \\
Consumption & 0.7339 & 0.9981 & 0.9991 \\
Investment & 0.8193 & 0.9446 & 0.5889 \\
Hours & 0.6521 & 0.9982 & 0.9992 \\
TB/Y Ratio & -0.2445 & -0.5024 & -0.2803 \\
CA/Y Ratio & -0.1185 & -0.4754 & -0.4505 \\
\hline
\end{tabular}

Notes: The first column refers to annual per capita Canadian data that have been logged (with the exception of the trade balance-output and current account-output ratios), and detrended using the HP filter with smoothing parameter $\lambda=100$, before computing the moments. The volatility statistics refers to the percentage standard deviation of the variable of interest. 


\section{APPENDIX:}

Table 4: Data Description:

POP: Quarterly Population, by Province (V1)

GDP: $\quad$ Gross Domestic Product (V1992067)

CNDG: $\quad$ Personal Expenditure on Non-durable Goods (V1992047)

IME: $\quad$ Investment in Machinery and Equipment (V1992056)

HOURS: Index of Hours Worked for all Jobs (V1409155)

CA: Total Current Account (V114421)

CNSVC: Personal Expenditure on Services (V1992048)

IRS: Investment on Residential Structures (V1992053)

INRS: Investment on Non-Residential Structures (V1992055)

EXP: Total Export of Goods and Services (V1992060)

IMP: $\quad$ Total Import of Goods and Services (V1992063)

CPI: $\quad$ Consumer Price Indexes, Non-durable Goods (V735592)

IPI: Industrial Product Price Indexes (V1575432)

IME: $\quad$ Investment in Machinery and Equipment, and Transportation Equipment (V1992133)

CAP: $\quad$ Flow and Stock of Fixed Non-Residential Capital (V1070258)

UTR: Industrial Capacity Utilization Rate (V142812)

Note: All data used are from the Canadian Socio-economic Informational and Management (CANSIM II) database. In parentheses are the CANSIM II labels for the series of interest. 
Table 5: Parameter Values Used in Tables Provided:

TFP Shocks: IST Shocks:

Table 1 \& 5:

$\begin{array}{lll}\rho_{i} & 0.8564 & 0.7818 \\ \sigma_{i} & 1.6100 & 2.6500 \\ \phi & 1.1831 & 1.0983\end{array}$

Table 2:

\begin{tabular}{lll}
$\rho_{i}$ & 0.7665 & 0.7818 \\
$\sigma_{i}$ & 1.7400 & 2.6500 \\
$\phi$ & 1.5000 & 9.2074 \\
& & \\
\hline
\end{tabular}

Note: $\sigma_{i}$ is presented as a percent. 